CLINICAL STUDY

\title{
Posterior pituitary (PP) evaluation in patients with anterior pituitary defect associated with ectopic PP and septo-optic dysplasia
}

\author{
Andrea Secco ${ }^{1, *}$, Anna Elsa Maria Allegri ${ }^{1, *}$, Natascia di Iorgi $^{1}$, Flavia Napoli $^{1}$, AnnaLisa Calcagno $^{1}$, Enrica Bertelli $^{1}$, \\ Irene Olivieri ${ }^{1}$, Giovanna Pala ${ }^{1}$, Stefano Parodi ${ }^{2}$, Roberto Gastaldi ${ }^{1}$, Andrea Rossi ${ }^{3}$ and Mohamad Maghnie ${ }^{1}$ \\ ${ }^{1}$ Department of Pediatrics, ${ }^{2}$ Epidemiology and Biostatistics Section, Scientific Directorate and ${ }^{3}$ Pediatric Neuroradiology, IRCCS G. Gaslini Institute, \\ University of Genova, Largo Gerolamo Gaslini 5, 16147 Genova, Italy
}

(Correspondence should be addressed to M Maghnie; Email: mohamadmaghnie@ospedale-gaslini.ge.it)

*(A Secco and A E M Allegri contributed equally to this work)

\begin{abstract}
Objective: Controversies exist about posterior pituitary (PP) function in subjects with ectopic PP (EPP) and with cerebral midline defects and/or their co-occurrence. We investigate water and electrolyte disturbances in patients at risk for PP dysfunction.

Design: The study was conducted in a single Pediatric Endocrinology Research Unit.

Methods: Forty-two subjects with childhood-onset GH deficiency were subdivided into five groups: normal magnetic resonance imaging ( $n=8$, group 1$)$; EPP $(n=15$, group 2$)$; septo-optic dysplasia (SOD) with normal PP ( $n=4$, group 3); EPP and SOD without ( $n=7$, group 4$)$, and with additional midline brain abnormalities $(n=8$, group 5$)$. At a mean age of $16.0 \pm 1.1$ years, they underwent a $120 \mathrm{~min}$ i.v. infusion with hypertonic 5\% saline and evaluation of plasma osmolality (Posm), arginine vasopressin (AVP), thirst score (in groups 1 and 2), and urinary osmolality were performed.

Results: Mean Posm and AVP significantly increased from baseline scores $(284.7 \pm 4.9 \mathrm{mosm} / \mathrm{kg}$ and $0.6 \pm 0.2 \mathrm{pmol} / \mathrm{l})$ to $120 \mathrm{~min}$ after saline infusion $(300.5 \pm 8.0 \mathrm{mosm} / \mathrm{kg}$ and $10.3 \pm 3.3 \mathrm{pmol} / \mathrm{l}$, $P<0.0001)$. Group 5 showed higher mean Posm and lower mean AVP at all time points $(P<0.0001)$. Mean thirst score did not show a significantly different trend between the groups 1 and 2 . Urine osmolality was above $750 \mathrm{mosm} / \mathrm{kg}$ in all but seven patients after osmotic challenge.

Conclusions: Patients with midline brain abnormalities and EPP have defective osmoregulated AVP. Patients with EPP and congenital hypopituitarism have normal PP function.

European Journal of Endocrinology 165 411-420
\end{abstract}

\section{Introduction}

Central diabetes insipidus (CDI), thirst abnormalities and water and electrolyte disorders have been reported in patients with structural hypothalamic-pituitary (HP) abnormalities and cerebral midline defects by magnetic resonance imaging (MRI). Controversies exist, however, regarding neurohypophyseal function in subjects with ectopic posterior pituitary (EPP), the most common condition associated with congenital anterior pituitary deficiencies (1-5). Several studies have shown abnormal $\mathrm{PP}$ function, ranging from reduced vasopressin release after osmotic challenge, hypodipsia, or polydipsia (6) to persistent nocturnal enuresis or symptomatic CDI, in both familial (7) and sporadic cases of hypopituitarism associated with either isolated GH deficiency (IGHD) or multiple pituitary hormone deficiencies (MPHD) $(6,8,9)$. Other studies which focused on the assessment of anterior pituitary function in patients with EPP have never reported water and electrolyte disturbances or CDI in these patient populations (1, 2, 10-15).

Osmoregulation defects have been identified in a number of congenital cerebral midline abnormalities (16-20). Specifically, septo-optic dysplasia (SOD) has been reported from its earliest descriptions as a condition associated with disorders of both anterior and PP function (4, 21-23). Moreover, several patients with SOD have a combination of midline defects and structural HP abnormalities such as anterior pituitary hypoplasia, pituitary stalk hypoplasia/agenesis with or without EPP (4) in the presence or absence of PP dysfunction; however, the diagnosis of these patients' various hypothalamic-PP disorders in the studies was based on standard procedures only. The etiology of SOD remains puzzling although the transcription factor homeobox gene expressed in embryonic stem cell (HESX1) might be involved (24).

The aim of our study is to investigate the relationship between PP function and its anatomy in determining 
water and electrolyte disturbances in patients with or without structural HP abnormalities in the presence or absence of cerebral midline defects. As standard procedures may fail or be unreliable for the identification of subtle water and electrolyte disorders, hypertonic saline and thirst score tests were used to provide useful information on hypothalamic-PP function.

\section{Materials and methods}

\section{Study population}

Forty-two subjects (19 females, 23 males) who were diagnosed during childhood with GHD $(n=23$; eight with idiopathic GHD and normal MRI, 15 with congenital GHD and EPP, and one previously diagnosed with familial form of CDI and EPP at MRI) or with SOD and pituitary hormone deficiencies including GHD $(n=19)$ were enrolled prospectively from the Pediatric Endocrinology Unit (Fig. 1). Their daily fluid intake and daily urinary output was evaluated $48 \mathrm{~h}$ before dynamic PP evaluation and ranged between 1750 and $2800 \mathrm{ml}$ and 1200 and $2100 \mathrm{ml}$ (lower than $30 \mathrm{ml} / \mathrm{kg}$ body weight in all subjects) respectively.

All were on adequate hormonal replacement at the time of recruitment to the study. The clinical and biochemical diagnosis of hypopituitarism was followed by a detailed MRI study of the HP and brain structures. The diagnosis of SOD was made by means of three criteria: the presence of optic nerve hypoplasia $(\mathrm{ONH})$, of midline neuroradiological abnormalities (such as agenesis of the corpus callosum and/or absence of the septum pellucidum), and of pituitary hypoplasia with pituitary hormone deficiency $(21,25-27)$. Owing to recurrent episodes of hyponatremia and seizures, treatment with desmopressin acetate (desamino-D-arginine-8-vasopressin (DDAVP)) was discontinued during the follow-up period (from 6 months to 3 years before the study) in six patients with SOD previously diagnosed with CDI; in these patients the diagnosis of CDI was made based on a random plasma osmolality (Posm) above $295 \mathrm{mosm} / \mathrm{kg}$

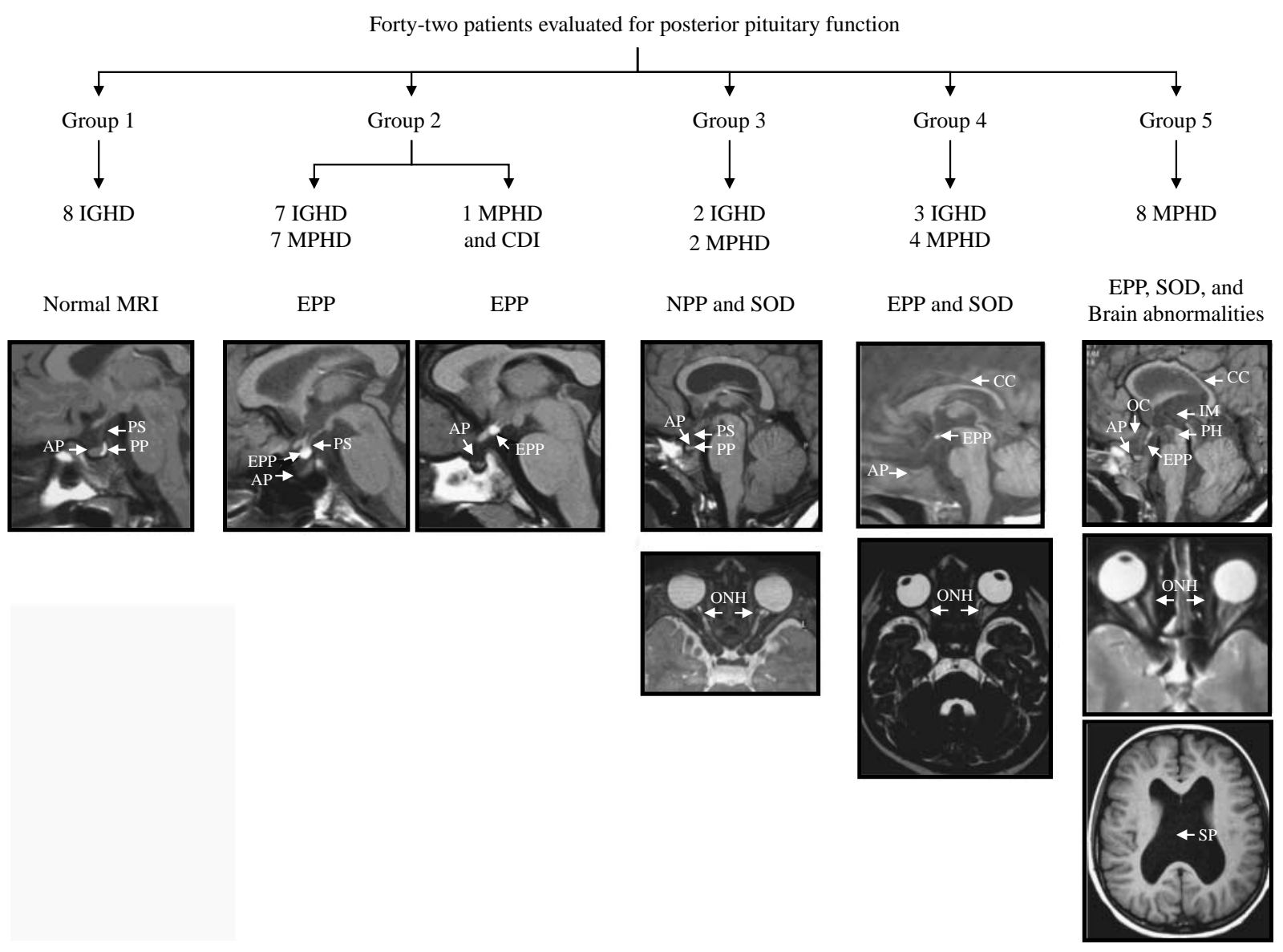

Figure $1 \mathrm{MRI}$ and endocrine features of 42 patients with GH deficiency. IGHD, isolated GH deficiency; MPHD, multiple pituitary hormone deficiencies; CDI, central diabetes insipidus; EPP, ectopic posterior pituitary; NPP, normally located posterior pituitary; SOD, septo-optic dysplasia; AP, anterior pituitary; PP, posterior pituitary; PS, pituitary stalk; ONH, optic nerve hypoplasia; CC, (thin) corpus callosum; OC, (absence of) optic chiasm; IM, (absence of) interthalamic mass; PH, pons hypoplasia; SP, (agenesis of) septum pellucidum. 
and a low urine osmolality during childhood in other hospitals. DDAVP treatment was also discontinued in the patient with familial CDI the night before the study.

The diagnosis of GHD was made at a mean age of $6.3 \pm 2.6$ years, based on a peak GH of $10 \mu \mathrm{g} / \mathrm{l}$ after at least two pharmacological stimulation tests, including insulin tolerance test (ITT) and glucagon or arginine test. Mean IGF1 at diagnosis was -3.11 0.97 standard deviation score (SDS) and mean height SDS was $-3.13 \pm 0.71$ according to Tanner's growth standards. The clinical and biochemical characteristics of the patients are summarized in Table 1.

All subjects underwent an evaluation of pituitary function. Central hypothyroidism was defined as low/inadequately low TSH concentration (reference values $0.5-4.0 \mathrm{mIU} / \mathrm{l})$ with low free thyroxine $\left(\mathrm{FT}_{4}\right.$; below $8.0 \mathrm{ng} / \mathrm{l})$. ACTH deficiency was defined as either a morning serum cortisol concentration of $100 \mathrm{nmol} / \mathrm{l}$ or an impaired cortisol serum concentration peak value of $550 \mathrm{nmol} / \mathrm{l}$ during ITT. Central hypogonadism was confirmed in both sexes by lack of puberty and no increase in serum FSH and LH (or slight increase with peak $\mathrm{LH}<\mathrm{FSH}$ ) after i.v. administration of GNRH. Ultrasonography was used to identify female patients with prepubertal internal genitalia. Basal serum samples were taken for determination of IGF1.

The hormonal work-up revealed IGHD in 21 subjects and MPHD in 21 subjects, one of whom was a female with familial CDI. All patients were being treated with recombinant human $\mathrm{GH}$ at conventional dosages and subjects with MPHD were receiving conventional therapy for pituitary defects with good adherence as revealed by normal serum concentration of $\mathrm{FT}_{4}$ and cortisol: $\mathrm{L}_{-} \mathrm{T}_{4}$ 75-200 $\mu \mathrm{g} /$ day, hydrocortisone 15-20 mg/day in two to three separate doses, testosterone enanthate 150-250 mg i.m. every 2 or 3 weeks for male subjects, and ethinyl estradiol or transdermal
$17 \beta$-estradiol patches with medroxyprogesterone acetate for female subjects. In the patient with familial CDI and DDAVP was administered orally three times daily.

\section{MRI evaluation}

Sagittal and coronal T1- and T2-weighted MRI images with $2-3 \mathrm{~mm}$ sections were obtained in all patients at the time of diagnosis and evaluated by the same experienced neuroradiologist (A R), who was blinded to all clinical and hormonal findings. The study cohort was subdivided into five groups according to their MRI features (Fig. 1). Eight subjects with IGHD showed a normal HP region (group 1). An isolated EPP was found in 15 subjects (group 2, eight IGHD, six MPHD, and one MPHD with familial CDI; father affected). Four subjects (group 3, two IGHD and two MPHD) showed SOD with normal PP location. EPP was associated with SOD in 15 patients, of whom seven (three IGHD and four MPHD) without (group 4) and eight MPHD with (group 5) additional and variable combination of brain abnormalities including hypoplasia of anterior commissure and/or the mesencephalon and/or pons hypoplasia, and/or absence or hypoplastic optic chiasm and/or absence of interthalamic mass (Table 1).

\section{Dynamic PP function evaluation}

At a mean age of $16.0 \pm 1.1$ years, all subjects underwent an i.v. osmotic challenge with hypertonic $5 \%$ saline $(\mathrm{NaCl}$, concentration $855 \mathrm{mmol} / \mathrm{l})$ infused at a rate of $0.05 \mathrm{ml} / \mathrm{kg}$ per min, according to the method described by Baylis \& Robertson (28).

To maintain adequate hydration, free access to food and fluids was allowed up to the morning of the tests.

Table 1 Clinical data of 42 subjects affected by GHD with or without septo-optic dysplasia and/or hypothalamic-pituitary abnormalities. Data are shown as mean \pm s.D.

\begin{tabular}{|c|c|c|c|c|c|c|c|}
\hline & \multicolumn{6}{|c|}{ Study population } & \multirow[b]{2}{*}{$P$} \\
\hline & Overall & Group 1 & Group 2 & Group 3 & Group 4 & Group 5 & \\
\hline \multicolumn{7}{|l|}{ GHD diagnosis } & \\
\hline Age (years) & $6.3 \pm 2.6$ & $8.6 \pm 1.4$ & $5.8 \pm 2.3$ & $2.9 \pm 0.5$ & $7.2 \pm 2.1$ & $5.2 \pm 2.8$ & 0.0027 \\
\hline Bone age (years) & $3.9 \pm 2.3$ & $6.1 \pm 1.3$ & $3.5 \pm 2.2$ & $1.0 \pm 0.0$ & $4.5 \pm 2.0$ & $3.2 \pm 2.4$ & 0.0045 \\
\hline Height (SDS) & $-3.13 \pm 0.71$ & $-2.91 \pm 0.85$ & $-3.11 \pm 0.56$ & $-3.63 \pm 0.59$ & $-3.09 \pm 0.42$ & $-3.23 \pm 1.03$ & NS \\
\hline $\begin{array}{l}\text { Hormone defects } \\
\text { (IGHD/MPHD) }\end{array}$ & $20 / 21$ & $8 / \overline{0}$ & $8 / \overline{7}$ & $2 / 2$ & $3 / \overline{4}$ & $0 / \overline{8}$ & \\
\hline Peak GH to ITT/glucagon $(\mu \mathrm{g} / \mathrm{l})$ & $2.2 \pm 1.3$ & $2.2 \pm 1.1$ & $2.4 \pm 1.2$ & $1.7 \pm 0.6$ & $1.3 \pm 1.1$ & $2.9 \pm 1.8$ & NS \\
\hline Peak GH to arginine $(\mu \mathrm{g} / \mathrm{l})$ & $2.1 \pm 2.7$ & $2.7 \pm 4.0$ & $1.5 \pm 1.1$ & $1.2 \pm 0.3$ & $1.3 \pm 1.0$ & $3.9 \pm 4.1$ & NS \\
\hline IGF1 (SDS) & $-3.11 \pm 0.97$ & $-2.76 \pm 0.83$ & $-2.98 \pm 0.64$ & $-2.53 \pm 0.57$ & $-3.76 \pm 0.93$ & $-3.36 \pm 1.48$ & NS \\
\hline \multicolumn{8}{|l|}{ At time of study } \\
\hline Age (years) & $16.0 \pm 1.1$ & $15.9 \pm 0.5$ & $17.1 \pm 1.0$ & $17.0 \pm 0.3$ & $17.2 \pm 1.6$ & $16.9 \pm 0.8$ & NS \\
\hline BMI $\left(\mathrm{kg} / \mathrm{m}^{2}\right)$ & $21.4 \pm 1.8$ & $20.8 \pm 2.0$ & $21.5 \pm 1.5$ & $22.4 \pm 1.7$ & $21.2 \pm 1.9$ & $21.7 \pm 2.0$ & NS \\
\hline
\end{tabular}

Group 1, normal MRI; Group 2, EPP; Group 3, NPP and SOD; Group 4, EPP and SOD; Group 5, EPP, SOD and brain abnormalities; MRI, magnetic resonance imaging; EPP, ectopic posterior pituitary; NPP, normally located posterior pituitary; SOD, septo-optic dysplasia; M, males; F, females; IGHD, isolated GH deficiency; MPHD, multiple pituitary hormone deficiencies; ITT, insulin tolerance test; BMI, body mass index; NS, not significant. 
The six SOD patients previously treated with DDAVP were classified into groups $3(n=1), 4(n=2)$, and $5(n=3)$.

The patients remained supine for $30 \mathrm{~min}$ before and throughout the test. A peripheral venous line was placed in a forearm vein and samples for Posm and arginine vasopressin (AVP) measurement were collected at time 0 and after $30,60,90$, and 120 min of $5 \%$ saline infusion. A thirst score, based on a $10 \mathrm{~cm}$ long visual analog scale according to the method described by Thompson et al. $(29,30)$, was calculated in groups 1 and 2 subjects (without visual impairment and/or developmental delay). Only at the end was free access to oral fluids allowed and thirst score was calculated after 10, 20, and $30 \mathrm{~min}$ in groups 1 and 2. Urine samples were collected before the start of saline infusion and by the end of the test for measurement of urinary osmolality (Uosm), urine output and the Uosm/Posm ratio.

All studies were performed in the morning starting between 0800 and $0830 \mathrm{~h}$. The study design was approved by local Ethics Committees and written informed consent was obtained from all patients before all procedures.

\section{Assays methods}

Posm was measured by the depression of freezing point method (Advanced Instruments Osmometer, model 3320, Norwood, MA, USA; resolution $1 \mathrm{mosm} / \mathrm{kg}$, repeatability: s.D. $\leq 2 \mathrm{mosm} / \mathrm{kg}$ between 0 and $400 \mathrm{mosm} / \mathrm{kg}$ ). Plasma AVP was determined by RIA after extraction from plasma by adsorption onto magnesium silicate (Florisil, U.S. Silica, Berkeley Springs, WV, USA), with intra- and inter-assay coefficient of variation 9.7 and $15.3 \%$, respectively; limit of detection, $0.3 \mathrm{pmol} / \mathrm{l}$ (31). All hormonal measurements were carried out by means of standard chemiluminescence. All samples from each individual subject were analyzed together at the same time. After centrifugation at $4{ }^{\circ} \mathrm{C}$, plasma was separated and stored at $-20{ }^{\circ} \mathrm{C}$.

\section{Statistical analysis}

Descriptive statistics were reported as means and s.D. for quantitative variables, while qualitative variables were described as absolute frequencies. Anthropometric data were expressed as absolute values or SDS, calculated with the formula (observed value - mean value for age and sex)/s.D. Pearson's correlation coefficient was estimated to evaluate the association among age, body mass index (BMI), and each clinical variable considered (namely: Posm, AVP, and thirst score). Time variation in mean values of blood concentration of clinical variables was evaluated by the ANOVA for repeated measures. A $P$ value of $<0.05$ was considered statistically significant. All tests were two-sided. Statistical analyses were performed by Stata for Windows Statistical Software (Stata release 11.0, Stata Corporation, College Station, TX, USA).

\section{Results \\ PP function evaluation}

The i.v. osmotic challenge was associated with an increase in Posm value above 295 mosm $/ \mathrm{kg}$ (level requested in the diagnostic work-up of CDI) (32) with no rise in plasma AVP levels confirming CDI in the female subject of group 2 with familial CDI and EPP, who was thus excluded from the statistical analysis.

In the remaining 41 subjects, mean Posm and AVP significantly increased significantly after $120 \mathrm{~min}$ of saline infusion $(P<0.0001)$. The temporal trend of increase was significantly different among the five groups $(P<0.0001)$ as shown in Fig. 2. Group 5 subjects showed significantly higher mean Posm at all time points of infusion compared with the other groups $(P<0.0001$; Fig. 2). Group 4 subjects showed a significantly higher mean Posm at the time points between 0 and $90 \mathrm{~min}$ (time $0^{\prime}, P=0.01 ; 30^{\prime}, P<0.0001 ; 60^{\prime}, P<0.0001 ; 90^{\prime}$, $P=0.01 ; 120^{\prime}, P=0.066$; Fig. 2 ).

While no significant difference was observed at baseline in mean AVP concentrations among the five groups, AVP reached the lowest levels in group 5 at all time points $(P<0.0001$; Fig. 2$)$. AVP concentrations in group 4 was not statistically different from those in groups 1, 2, and 3 at each time point.

In all 41 patients, mean Posm/AVP ratio decreased significantly at $120 \mathrm{~min}(P<0.0001)$, with different temporal trends between the groups $(P=0.001)$. Group 5 subjects demonstrated significantly higher Posm/AVP ratios at all time points compared with the others $(P<0.0001$; Fig. 2).

Posm, AVP and their ratio did not statistically differ between subjects with MPHD and IGHD in all study groups (data not shown). No gender differences were detected among all evaluated parameters.

Mean thirst score increased significantly in groups 1 and 2 during the osmotic challenge (time $0^{\prime}, 1.4$ $\pm 0.4 \mathrm{~cm}$ and $120^{\prime}, 8.2 \pm 0.9 \mathrm{~cm}$ ) and progressively returned to near baseline levels after $30 \mathrm{~min}$ of free oral fluid access $(1.4 \pm 0.4 ; P<0.0001)$, without statistical differences (Fig. 2).

Baseline inter-individual urine osmolality was extremely variable ranging from 75 to $560 \mathrm{mosm} / \mathrm{kg}$. Urine osmolality at the end of the hypertonic saline test was above $750 \mathrm{mosm} / \mathrm{kg}$ in all patients with the exception of one from group $4(438 \mathrm{mosm} / \mathrm{kg})$ and six from group 5 $(425,432,441,458,482$, and $564 \mathrm{mosm} / \mathrm{kg}$ respectively). In these patients, neither polydipsia nor polyuria had been previously documented. Mean Uosm and Uosm/Posm ratio were significantly lower in group 5 

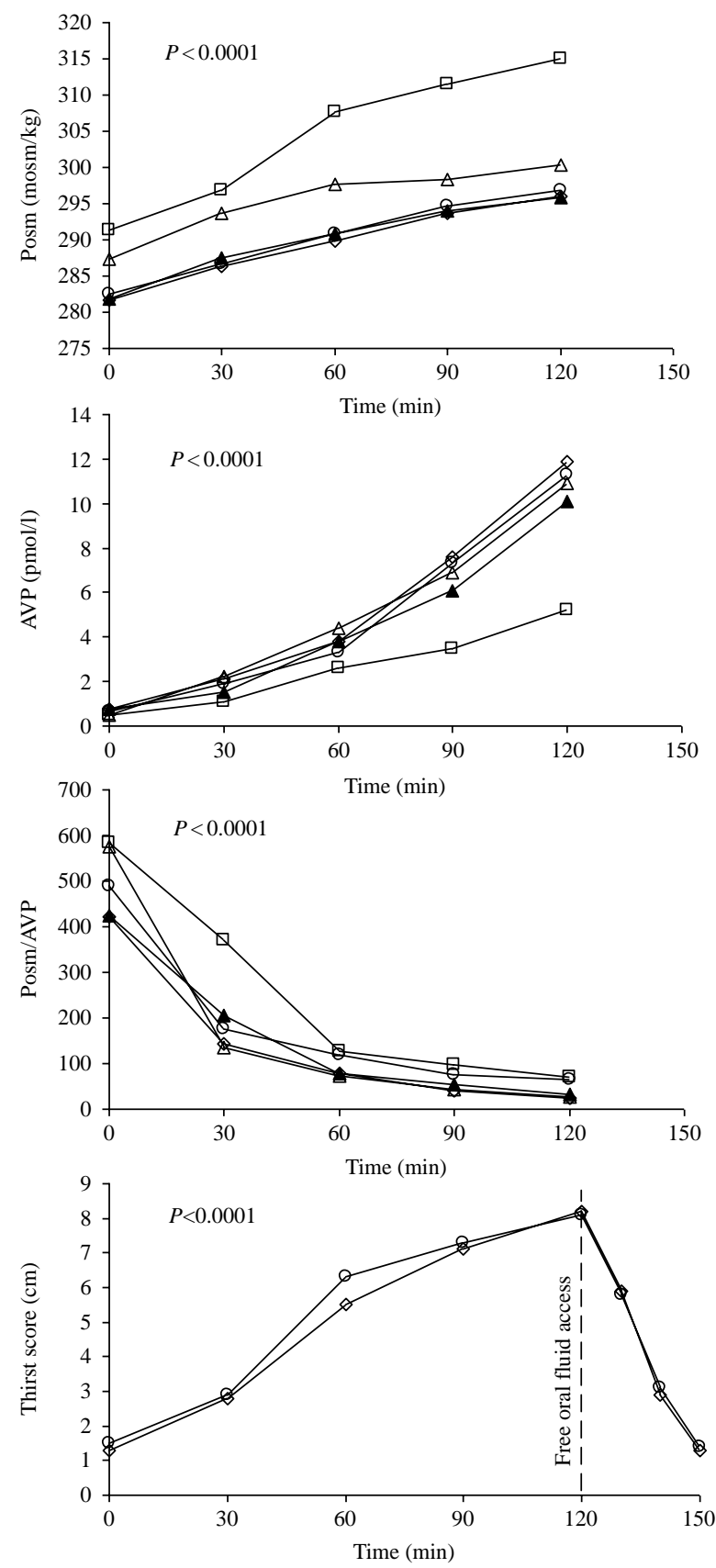

Figure 2 Mean plasma osmolality (Posm), vasopressin (AVP), Posm/AVP ratio, and thirst score during osmotic challenge and free fluid access. See text for all $P$ values. Open diamond, group 1: normal MRI; open circle, group 2: isolated EPP without other HP anomalies; filled triangle, group 3: normal posterior pituitary with SOD; open triangle, group 4: EPP with SOD; open square, group 5: EPP with SOD and additional brain abnormalities.

compared with the others at both baseline and after osmotic challenge, while no differences were observed in mean urine output among the five groups (although group 5 showed a slightly higher urinary volume not reaching statistical significance). All biochemical data during the osmotic challenge are summarized in Table 2.

\section{Correlations}

A significant association between Posm and vasopressin response was found at each time point of the osmotic challenge test, independent of the MRI picture. The association was equally significant in subjects with normal MRI (group 1: $r=0.84, P<0.0001$ ), isolated EPP (group 2: $r=0.67, P<0.0001$ ), isolated SOD (group 3: $r=0.83, P<0.0001$ ), or EPP plus SOD (group 4: $r=0.79, P<0.0001$ ) with the increase in Posm never exceeding $305 \mathrm{mosm} / \mathrm{kg}$. The association between Posm and vasopressin response was weaker in those with SOD, EPP, and additional brain abnormalities (group 5: $r=0.51, P=0.02$ ) with high baseline osmolality and a delayed (Posm $>300 \mathrm{mosm} / \mathrm{kg}$ ) and inadequate increase of AVP (Fig. 3). The normal range of AVP for Posm values is represented in Fig. 3 with shaded areas based on the report by Robertson (32).

No statistically significant correlation was found among Posm, AVP, and thirst score (groups 1 and 2) or between each of these variables and age or BMI.

\section{Discussion}

Although assessing PP function by determining AVP response to graded osmotic stimulation is a wellrecognized procedure (33), this study is, to our knowledge, the first one designed with the purpose of systematically evaluating the relationship between PP function and brain neuroanatomy in patients at risk for various water disorders. Despite the current awareness of water homeostasis impairment ranging from subtle defects of PP function to complete forms of CDI and/or hypernatremia in patients with cerebral midline defects (including SOD) $(4,16-18,21-23)$, the underlying pathophysiologic mechanisms have not yet been clearly defined (34).

The results for baseline Posm in our cohort suggest that PP function was not affected either in subjects with GHD and normal PP location or in those with EPP or SOD and normally located PP. Conversely, subjects with SOD and EPP or with SOD, EPP, and complex brain abnormalities showed baseline Posm values suggestive of osmoregulation impairment of thirst and/or water intake.

In our study, hypertonic saline infusion proved to be a reliable and very well-tolerated approach to the assessment of PP function because it requires less time than a standard water deprivation test and offers the chance to explore the hemodynamic effects of AVP osmoregulation. Subjects belonging to groups 1, 2, and 3 showed a similar curve slope with a mean Posm below $295 \mathrm{mosm} / \mathrm{kg}$ from baseline to $90 \mathrm{~min}$ after saline infusion with further increase at the time point of $120 \mathrm{~min}$. Conversely, the increase in mean Posm documented within the first hour of saline infusion in group 5 as well as the slightly higher urine output 
Table 2 Biochemical evaluation and thirst score of study subjects before and after the i.v. osmotic challenge. Data are shown as mean \pm s.D.

\begin{tabular}{|c|c|c|c|c|c|c|c|}
\hline & \multicolumn{6}{|c|}{ Study population } & \multirow[b]{2}{*}{$\boldsymbol{P}$} \\
\hline & Overall & Group 1 & Group 2 & Group 3 & Group 4 & Group 5 & \\
\hline \multicolumn{8}{|c|}{ i.v. osmotic challenge time $0^{\prime}$} \\
\hline $\mathrm{Na}^{+}(\mathrm{mEq} / \mathrm{l})$ & $139.6 \pm 5.1$ & $136.4 \pm 1.9$ & $136.2 \pm 1.9$ & $136.8 \pm 3.5$ & $139.3 \pm 3.2$ & $144.8 \pm 2.7$ & $<0.0001$ \\
\hline Posm (mosm/kg) & $284.7 \pm 4.9$ & $281.6 \pm 3.0$ & $282.1 \pm 3.3$ & $281.8 \pm 6.2$ & $287.3 \pm 2.1$ & $291.4 \pm 1.8$ & $<0.0001$ \\
\hline AVP (pmol/l) & $0.6 \pm 0.2$ & $0.8 \pm 0.3$ & $0.6 \pm 0.2$ & $0.8 \pm 0.3$ & $0.5 \pm 0.0$ & $0.5 \pm 0.0$ & NS \\
\hline Posm/AVP & $500.9 \pm 126.9$ & $422.8 \pm 151.6$ & $483.9 \pm 133.3$ & $424.0 \pm 167.8$ & $574.6 \pm 4.1$ & $582.8 \pm 3.5$ & \\
\hline Thirst score $(\mathrm{cm})$ & $1.4 \pm 0.4$ & $1.3 \pm 0.4$ & $1.4 \pm 0.4$ & $\mathrm{NE}$ & $\mathrm{NE}$ & $\mathrm{NE}$ & NS \\
\hline Uosm (mosm/kg) & $412.4 \pm 120.6$ & $507.2 \pm 124.3$ & $489.5 \pm 153.6$ & $477.6 \pm 148.5$ & $463.8 \pm 145.9$ & $107.8 \pm 32.7$ & $<0.0001$ \\
\hline \multicolumn{8}{|c|}{ i.v. osmotic challenge time $30^{\prime}$} \\
\hline Posm (mosm $/ \mathrm{kg})$ & $289.7 \pm 5.0$ & $286.4 \pm 1.8$ & $286.2 \pm 2.2$ & $287.5 \pm 5.1$ & $293.6 \pm 1.3$ & $296.8 \pm 2.9$ & $<0.0001$ \\
\hline AVP $(p m o l / l)$ & $1.8 \pm 0.6$ & $2.1 \pm 0.5$ & $2.0 \pm 0.5$ & $1.5 \pm 0.4$ & $2.2 \pm 0.4$ & $1.1 \pm 0.6$ & $<0.0001$ \\
\hline Posm/AVP & $193.5 \pm 125.6$ & $141.9 \pm 34.2$ & $147.1 \pm 31.9$ & $204.3 \pm 64.3$ & $135.6 \pm 19.8$ & $371.3 \pm 195.0$ & $<0.0001$ \\
\hline Thirst score $(\mathrm{cm})$ & $2.8 \pm 0.6$ & $2.8 \pm 0.6$ & $2.8 \pm 0.6$ & $\mathrm{NE}$ & $\mathrm{NE}$ & NE & NS \\
\hline \multicolumn{8}{|c|}{ i.v. osmotic challenge time $60^{\prime}$} \\
\hline Posm (mosm/kg) & $295.0 \pm 7.2$ & $289.9 \pm 1.2$ & $290.4 \pm 2.1$ & $290.8 \pm 4.2$ & $297.7 \pm 1.8$ & $307.6 \pm 1.5$ & $<0.0001$ \\
\hline AVP $(\mathrm{pmol} / \mathrm{l})$ & $3.6 \pm 1.0$ & $3.8 \pm 0.7$ & $3.5 \pm 0.7$ & $3.8 \pm 0.6$ & $4.4 \pm 1.3$ & $2.6 \pm 0.7$ & $<0.0001$ \\
\hline Posm/AVP & $89.4 \pm 27.0$ & $77.9 \pm 12.4$ & $85.5 \pm 14.9$ & $79.4 \pm 15.0$ & $72.2 \pm 20.7$ & $127.5 \pm 30.8$ & $<0.0001$ \\
\hline Thirst score $(\mathrm{cm})$ & $5.9 \pm 1.3$ & $5.5 \pm 1.1$ & $6.2 \pm 1.3$ & $\mathrm{NE}$ & $\mathrm{NE}$ & $\mathrm{NE}$ & NS \\
\hline \multicolumn{8}{|c|}{ i.v. osmotic challenge time $90^{\prime}$} \\
\hline Posm (mosm/kg) & $298.1 \pm 7.3$ & $293.6 \pm 2.3$ & $294.1 \pm 2.6$ & $294.0 \pm 4.5$ & $298.4 \pm 2.9$ & $311.5 \pm 1.6$ & $<0.0001$ \\
\hline AVP (pmol/l) & $6.6 \pm 2.1$ & $7.6 \pm 1.1$ & $7.8 \pm 1.6$ & $6.1 \pm 2.1$ & $6.9 \pm 0.6$ & $3.5 \pm 1.2$ & $<0.0001$ \\
\hline Posm/AVP & $52.9 \pm 27.9$ & $39.3 \pm 6.2$ & $39.3 \pm 8.5$ & $53.7 \pm 22.6$ & $43.3 \pm 3.6$ & $98.1 \pm 32.1$ & $<0.0001$ \\
\hline Thirst score $(\mathrm{cm})$ & $7.1 \pm 0.6$ & $7.1 \pm 0.6$ & $7.2 \pm 0.6$ & NE & $\mathrm{NE}$ & NE & NS \\
\hline \multicolumn{8}{|c|}{ i.v. osmotic challenge time $120^{\prime}$} \\
\hline Posm (mosm/kg) & $300.5 \pm 8.0$ & $296.0 \pm 3.3$ & $296.3 \pm 3.3$ & $295.8 \pm 5.6$ & $300.3 \pm 2.5$ & $315.0 \pm 2.7$ & $<0.0001$ \\
\hline AVP $(\mathrm{pmol} / \mathrm{l})$ & $10.3 \pm 3.3$ & $11.9 \pm 2.0$ & $12.1 \pm 2.2$ & $10.1 \pm 3.2$ & $10.9 \pm 1.3$ & $5.2 \pm 1.9$ & $<0.0001$ \\
\hline Posm/AVP & $35.2 \pm 22.3$ & $25.6 \pm 4.3$ & $25.3 \pm 4.5$ & $31.7 \pm 11.0$ & $28.0 \pm 3.3$ & $70.3 \pm 30.8$ & $<0.0001$ \\
\hline Thirst score (cm) & $8.1 \pm 0.7$ & $8.1 \pm 0.8$ & $8.0 \pm 0.7$ & NE & NE & NE & NS \\
\hline Uosm (mosm/kg) & $802.5 \pm 170.9$ & $889.3 \pm 84.9$ & $884.8 \pm 76.8$ & $855.3 \pm 68.4$ & $807.1 \pm 167.4$ & $541.3 \pm 144.4$ & $<0.0001$ \\
\hline Urine output (ml) & $261.6 \pm 70.4$ & $247.5 \pm 89.4$ & $251.4 \pm 69.5$ & $263.8 \pm 62.6$ & $256.4 \pm 75.9$ & $296.9 \pm 53.2$ & NS \\
\hline Uosm/Posm & $2.7 \pm 0.6$ & $3.0 \pm 0.3$ & $3.0 \pm 0.2$ & $2.9 \pm 0.2$ & $2.7 \pm 0.6$ & $1.7 \pm 0.5$ & $<0.0001$ \\
\hline \multicolumn{8}{|c|}{ Free oral fluid access } \\
\hline Thirst score $(\mathrm{cm})$ & $1.4 \pm 0.4$ & $1.3 \pm 0.4$ & $1.4 \pm 0.4$ & NE & NE & NE & NS \\
\hline
\end{tabular}

Group 1, normal MRI; Group 2, EPP; Group 3, NPP and SOD; Group 4, EPP and SOD; Group 5, EPP, SOD and brain abnormalities; MRI, magnetic resonance imaging; EPP, ectopic posterior pituitary; NPP, normally located posterior pituitary; SOD, septo-optic dysplasia; Na ${ }^{+}$, plasma sodium; Posm, plasma osmolality; AVP, arginine vasopressin; Uosm, urine osmolality; NS, not significant; NE, not evaluated.

(although not significant), was compatible with impairment of hypothalamic-neurohypophyseal function. In addition, despite a significant and constant trend toward an increase in Posm values during the entire test in group 5, the slope of the curves in both groups 5 and 4 was markedly dissimilar with an earlier increase in Posm overcoming the mean value of $295 \mathrm{mosm} / \mathrm{kg}$ after $60 \mathrm{~min}$ in group 4 compared with groups 1,2 , and 3. We think that the pattern of Posm increase, as well as the higher Posm/AVP ratio and the early marked reduction in Posm/AVP ratio at $30 \mathrm{~min}$ in group 4 patients compared with the other groups may represent a subtle impairment/differing sensitivity at the level of thirst and/or vasopressin osmoreceptor regulation and/or AVP secretion. Despite the fact that baseline AVP concentration was low in all subjects, the possibility of 'chronic dehydration' cannot be entirely ruled out, although clinical features and biochemical parameters such as hematocrit, blood urea, and renin activity (data not shown) were within the normal range; this should also exclude a relevant hemodynamic effect on AVP production at the time of the study.

Low or undetectable plasma AVP concentrations were documented at baseline in all subjects despite the presence of a significantly higher mean Posm in groups 4 and 5; this suggests that (except in the case of patients with hypernatremia and/or baseline Posm above $295 \mathrm{mosm} / \mathrm{kg}$ ) neither AVP nor random Posm measurements are sensitive enough to identify patients with impairment of PP function. In addition, during hypertonic saline infusion, mean plasma AVP levels were not dissimilar among groups 1, 2, 3, and 4 at all time points, whereas group 5 patients showed the lowest AVP concentrations.

The AVP levels reached by group 5 compared with the other groups, as well as the highest Posm levels documented in this cohort, are compatible with inappropriately low AVP concentrations for the corresponding Posm suggesting a relative AVP deficiency. These data, although not supported by a thirst study for 

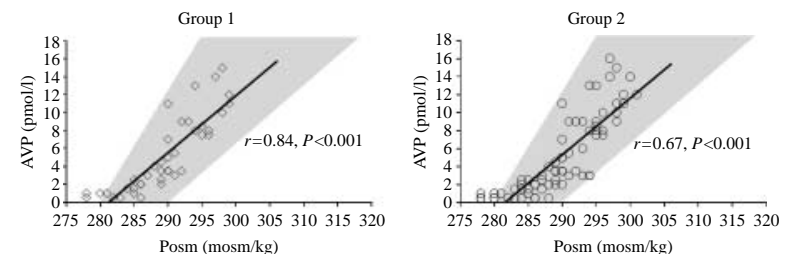

Posm $(\mathrm{mosm} / \mathrm{kg})$
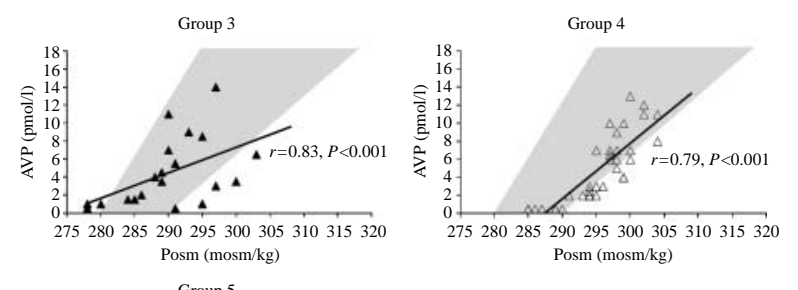

Group 5

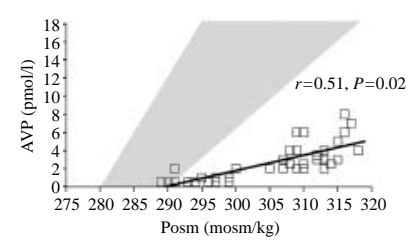

Figure 3 Regression analyses between plasma osmolality and vasopressin in subjects with: open diamond, group 1: normal MRI open circle, group 2: isolated EPP without other HP anomalies; filled triangle, group 3: normal posterior pituitary with SOD; open triangle, group 4: EPP with SOD; open square, group 5: EPP with SOD and additional brain abnormalities. Each graph shows the cumulative responses during osmotic challenge test. Shaded area, normal range of vasopressin values (32).

patients' visual impairment, are strongly indicative of at least a defect in osmoregulation of AVP secretion. In addition, the fact that Uosm ranged from over $400 \mathrm{mosm} / \mathrm{kg}$ to more than 750 in group 5 patients supports such a hypothesis. The highest baseline Posm/AVP ratio observed in group 5 and the different pattern of decrease during hypertonic saline infusion might indicate osmoreceptor dysregulation.

What is the underlying role of PP anatomy in the regulation of water homeostasis in our cohort? Our study demonstrated that, except for the patient with familial CDI associated with EPP and hypopituitarism, isolated EPP is not responsible per se for thirst and electrolyte disturbances. Our patient with familial CDI and hypopituitarism associated with EPP resembles the three cases reported by Yagi et al. (7), suggesting that CDI, hypopituitarism and EPP probably constitute an entirely different entity; this conclusion is based, on the one hand, in the absence of AVP and wolframin gene mutation in the family (data not shown) and, on the other hand, on normal PP function and thirst score in all group 2 patients with congenital hypopituitarism and EPP. The identification of PP hyperintensity in the patient with EPP and CDI is online with what it has been reported in the autosomal dominant forms of CDI where the presence of PP hyperintensity does not necessarily indicate that the functional integrity of the hypothalamic-neurohypophyseal axis is preserved (15-17).

Our data in patients with hypopituitarism associated with EPP are in contrast with the few published papers on PP function which show milder to overt forms of CDI $(6,8,9)$. In particular, compared with those with larger EPP or those with orthotopic PP, subjects with MPHD and small EPP size ( $<5 \mathrm{~mm}$ in T1 MRI images) have been described with various forms of PP dysfunction (8). In another report, data from an i.v. osmotic challenge showed that ten of 12 patients with EPP and anterior pituitary defects had persistent enuresis and/or nearly absent or unpredictable AVP response in the absence of overt CDI (6); CDI has also been documented after water deprivation test in $43 \%$ of patients with hypopituitarism and small EPP in a recent paper (9) (Table 3).

Systematic PP evaluation has never been carried out in patients with SOD and all reported studies focus on the presence or absence of optic nerve abnormalities, the presence or absence of septum pellucidum or corpus callosum without categorization based on additional brain defects. In our study, the 'SOD model', thanks to its heterogeneity and to the detailed neuroimaging examination, offers an excellent opportunity to evaluate the difference in osmoregulatory response in subjects with or without EPP and in those with EPP and severe brain abnormalities. While our patients with SOD and normal PP location showed PP function that was not dissimilar from patients with hypopituitarism and isolated EPP (group 2), hyperosmolality characterizes those patients with SOD and EPP and those with complex brain anomalies, indicating that SOD patients with EPP are more prone to developing osmoreceptor disturbances. In these latter patients the identification of PP hyperintensity was compatible with the diagnosis of hypothalamic dysfunction rather than with CDI, the latter being associated with a loss of PP signal (15-17).

Our data cannot be compared with those described in the literature $(4,23,35)$ as the frequency of CDI in SOD has been reported in as high as $6-38 \%$ of patients with SOD (Table 3). In particular, among previously described patients, $38 \%$ of 24 patients with SOD showed CDI, although a water deprivation test was performed in only 12 of the 24 subjects (23). It is worth pointing out that five of these latter CDI patients had an impaired sense of thirst and hypernatremia treated with DDAVP and followed by at least one or more episodes of seizures and hyponatremia; this may indicate that as is the case for our six patients, the water disturbances were most likely due to osmoreceptor/thirst abnormalities rather than to a complete AVP deficiency. In a large cohort of 170 patients with congenital hypopituitarism with or without $\mathrm{ONH}$, CDI was reported in $13 \%$ of patients, with a higher prevalence $(27 \%)$ in those with $\mathrm{ONH}$ compared with the $5 \%$ of those without $\mathrm{ONH}$ (4). In the paper by Cameron et al. (35), CDI was reported in six (24\%) of 25 patients with SOD with variable midline abnormalities including corpus callosum and/or septum pellucidum 
Table 3 Comparison between results of previous reports evaluating posterior pituitary function in subjects with different hypothalamicpituitary abnormalities.

\begin{tabular}{|c|c|c|c|c|c|}
\hline Papers & Subjects & MRI & Hormone defects & Procedure & Results \\
\hline Lukezic et al. (6) & $\begin{array}{l}15 \text { (3 excluded } \\
\text { from analysis) }\end{array}$ & $\begin{array}{l}\text { APH, EPP, PSA, or } \\
\text { thin PS }\end{array}$ & $\begin{array}{l}11 \mathrm{MPHD} \\
4 \mathrm{IGHD}\end{array}$ & $5 \% \mathrm{NaCl}$ infusion & $\begin{array}{l}10 \text { subjects with } \\
\text { abnormal AVP } \\
\text { secretion (worse in } \\
\text { MPHD) }\end{array}$ \\
\hline $\begin{array}{l}\text { Yamanaka } \\
\text { et al. (8) }\end{array}$ & $\begin{array}{l}20 \text { complete } \\
\text { GHD }\end{array}$ & $\begin{array}{l}\text { Transected pituitary } \\
\text { stalk and small } \\
(<5 \mathrm{~mm}) \text {, large } \\
(>5 \mathrm{~mm}) \text {, or no } \\
\text { visible EPP }\end{array}$ & $\begin{array}{l}13 \mathrm{MPHD} \\
7 \mathrm{IGHD}\end{array}$ & $\begin{array}{l}\text { Water deprivation } \\
5 \% \mathrm{NaCl} \text { infusion }\end{array}$ & $\begin{array}{l}\text { Lower Uosm and AVP } \\
\text { in small EPP Overt } \\
\text { CDI when no visible } \\
\text { EPP } \\
\text { Lower peak AVP in } \\
\text { small EPP }\end{array}$ \\
\hline Li et al. (9) & 125 & $\begin{array}{l}\text { EPP, absence of } \\
\text { PPBS, normally } \\
\text { located PP (CDI } \\
\text { patients) }\end{array}$ & $\begin{array}{l}125 \mathrm{MPHD} \text { of whom } \\
48 \mathrm{CDI}\end{array}$ & Water deprivation & $\begin{array}{l}\text { CDI in } 43 \% \text { with small } \\
\text { EPP and in all but } \\
\text { one with absent } \\
\text { PPBS }\end{array}$ \\
\hline Mehta et al. (4) & 170 & $\begin{array}{l}\text { APH, PSA, EPP, } \\
\text { corpus callosum, } \\
\text { and septum } \\
\text { pellucidum } \\
\text { abnormalities, ONH } \\
\text { (84 subjects), in } \\
\text { various combination }\end{array}$ & $\begin{array}{l}96 \% \mathrm{GH} \\
29 \% \mathrm{FSH} / \mathrm{LH} \\
56 \% \mathrm{TSH} \\
53.3 \mathrm{ACTH} \\
\text { deficiency } \\
13 \% \mathrm{CDI}\end{array}$ & $\begin{array}{l}\text { Water deprivation in } \\
\text { symptomatic patients }\end{array}$ & $\begin{array}{l}13 \% \text { CDI }(27 \% \text { of } \\
\text { those with ONH and } \\
5 \% \text { without } \mathrm{ONH})\end{array}$ \\
\hline Masera et al. (22) & 24 & $\begin{array}{l}\text { SOD } \pm \text { agenesis of } \\
\text { corpus callosum } \\
\text { ( } C_{\mathrm{T}} \text { data) }\end{array}$ & $\begin{array}{l}20 \mathrm{GH} \\
14 \mathrm{ACTH} \\
10 \mathrm{FSH} / \mathrm{LH} \\
\text { deficiency }\end{array}$ & $\begin{array}{l}\text { Water deprivation } \\
\text { (performed in 12) }\end{array}$ & $\begin{array}{l}9 \text { (38\%) CDI, of whom } \\
5 \text { with hypodipsia } \\
\text { and hypernatremia } \\
\text { poorly responsive to } \\
\text { DDAVP treatment, } \\
\text { followed by hypo- } \\
\text { natremic seizures }\end{array}$ \\
\hline Cameron et al. (32) & 40 & $\begin{array}{l}\text { Cerebral midline } \\
\text { abnormalities (of } \\
\text { whom } 18 \text { SOD } \\
\text { without and seven } \\
\text { SOD with septum } \\
\text { pellucidum } \\
\text { abnormalities) }\end{array}$ & $\begin{array}{l}26 \mathrm{MPHD} \\
10 \mathrm{IGHD} \\
4 \text { normal GH }\end{array}$ & $\begin{array}{l}\text { Water deprivation in } \\
\text { symptomatic patients } \\
\text { Morning Posm and } \\
\text { Uosm in asympto- } \\
\text { matic patients }\end{array}$ & $\begin{array}{l}6 \text { CDI out of } 25 \text { SOD } \\
\text { ( } 5 \text { without and } 1 \\
\text { with septum pelluci- } \\
\text { dum abnormalities) }\end{array}$ \\
\hline Antonini et al. (33) & 18 & $\begin{array}{l}\text { Cerebral midline } \\
\text { abnormalities (of } \\
\text { whom } 11 \text { SOD) }\end{array}$ & $\begin{array}{l}72 \% \mathrm{GH} \\
66 \% \mathrm{TSH} \\
55 \% \mathrm{FSH} / \mathrm{LH} \\
27 \% \mathrm{CDI}\end{array}$ & Water deprivation & $27 \% \mathrm{CDI}$ \\
\hline
\end{tabular}

$\mathrm{APH}$, anterior pituitary hypoplasia; EPP, ectopic posterior pituitary; PSA, pituitary stalk agenesis; PS, pituitary stalk; MPHD, multiple pituitary hormone deficiency; IGHD, isolated GH deficiency; AVP, arginine vasopressin; PPBS, posterior pituitary bright spot; CDI, central diabetes insipidus; ONH, optic nerve hypoplasia; SOD, septo-optic dysplasia; $C_{\mathrm{T}}$, computed tomography.

involvement. Finally, in the series by Antonini et al. (36), in 18 patients with midline cerebral defects, five subjects (27\%) showed deficiencies of both anterior and posterior function, with one of them affected by hypodipsia and hypernatremia.

The limitations of our study are the relatively small size of the cohort in such rare diseases and the low number of patients with SOD and normal PP location; the latter situation meant that it was not possible to draw a firm conclusion for this group and this in turn means that a multivariate analysis was not feasible. However, we believe that the information gleaned from the data clearly outweigh these limitations. In particular, the lack of thirst assessment due to visual impairment in patients with SOD made it impossible for us to completely rule out eventual damage of the central osmoreceptors involved in thirst perception which are anatomically distinct from those regulating AVP (37). In addition, the clinical implications in the management of SOD patients with electrolyte disturbances and hypothalamic dysfunction are quite significant to avoid incorrect diagnoses and possibly harmful treatment. DDAVP treatment is not advisable in these patients to avoid hyponatremia leading to seizures. Regular monitoring of water intake and serum electrolytes represents the best management in the presence of relative AVP deficiency while low DDAVP dosage should be reserved to patients with adipsia or to those who might develop polyuria and polydipsia.

In conclusion, our data suggest that the most common PP dysfunction is hyperosmolality and relative AVP deficiency characterizing patients with SOD, complex brain abnormalities and EPP; this type of dysfunction seems to involve damage to the 
osmoreceptors that regulate AVP synthesis and possibly the PP. Our study also confirms that patients with EPP and congenital hypopituitarism have normal PP function.

\section{Declaration of interest}

The authors declare that there is no conflict of interest that could be perceived as prejudicing the impartiality of the research reported.

\section{Funding}

S Parodi is recipient of a grant from the Italian Neuroblastoma Foundation (Fondazione Italiana per la Lotta al Neuroblastoma).

\section{References}

1 di Iorgi N, Secco A, Napoli F, Calandra E, Rossi A \& Maghnie M. Developmental abnormalities of the posterior pituitary gland. Endocrine Development $2009 \quad 14 \quad 83-94 . \quad$ (doi:10.1159/ 000207479)

2 Maghnie M, Ghirardello S \& Genovese E. Magnetic resonance imaging of the hypothalamus-pituitary unit in childrensuspected of hypopituitarism: who, how and when toinvestigate. Journal of Endocrinological Investigation 200427 496-509.

3 Maghnie M, Rossi A, DiIorgi N, Gastaldi R, Tortori-Donati P \& Lorini R. Hypothalamic-pituitary magnetic resonance imaging in growth hormone deficiency. Expert Review of Endocrinology \& Metabolism 2006 1 1-11. (doi:10.1586/17446651.1.1.1)

4 Mehta A, Hindmarsh PC, Mehta H, Turton JP, Russell-Eggitt I, Taylor D, Chong WK \& Dattani MT. Congenital hypopituitarism: clinical, molecular and neuroradiological correlates. Clinical Endocrinology $2009 \mathbf{7 1}$ 376-382. (doi:10.1111/j.1365-2265. 2009.03572.x)

5 Triulzi F, Scotti G, di Natale B, Pellini C, Lukezic M, Scognamiglio M \& Chiumello G. Evidence of a congenital midline brain anomaly in pituitary dwarfs: a magnetic resonance imaging study in 101 patients. Pediatrics 199493 409-416.

6 Lukezic M, Righini V, Di Natale B, De Angelis R, Norbiato G, Bevilacqua M \& Chiumello G. Vasopressin and thirst in patients with posterior pituitary ectopia and hypopituitarism. Clinical Endocrinology $2000 \quad 53 \quad 77-83 . \quad$ (doi:10.1046/j.1365-2265. 2000.01030.x)

7 Yagi H, Nagashima K, Miyake H, Tamai S, Onigata K, Yutani S \& Kuroume T. Familial congenital hypopituitarism with central diabetes insipidus. Journal of Clinical Endocrinology and Metabolism 199478 884-889. (doi:10.1210/jc.78.4.884)

8 Yamanaka C, Momoi T, Fujisawa I, Kikuchi K, Kaji M, Yorifuji T, Sasaki H, Sudo M, Konishi J \& Mikawa H. Neurohypophyseal function of an ectopic posterior lobe in patients with growth hormone deficiency. Acta Endocrinologica 1990122 664-670. (doi:10.1530/acta.0.1220664)

9 Li G, Shao P, Sun X, Wang Q \& Zhang L. Magnetic resonance imaging and pituitary function in children with panhypopituitarism. Hormone Research in Pediatrics 201073 205-209. (doi:10. $1159 / 000284363)$

10 Chen S, Leger J, Garel C, Hassan M \& Czernichow P. Growth hormone deficiency with ectopic neurohypophysis: anatomical variations and relationship between the visibility of the pituitary stalk asserted by magnetic resonance imaging and anterior pituitary function. Journal of Clinical Endocrinology and Metabolism 199984 2408-2413. (doi:10.1210/jc.84.7.2408)

11 Leger J, Danner S, Simon D, Garel C \& Czernichow P. Do all patients with childhood-onset growth hormone deficiency (GHD) and ectopic neurohypophysis have persistent GHD in adulthood? Journal of Clinical Endocrinology and Metabolism 200590 650-656. (doi:10.1210/jc.2004-1274)
12 di Iorgi N, Secco A, Napoli F, Tinelli C, Calcagno A, Fratangeli N, Ambrosini L, Rossi A, Lorini R \& Maghnie M. Deterioration of growth hormone $(\mathrm{GH})$ response and anterior pituitary function in young adults with childhood-onset GH deficiency and ectopic posterior pituitary: a two-year prospective follow-up study. Journal of Clinical Endocrinology and Metabolism 200792 3875-3884. (doi:10.1210/jc.2007-1081)

13 Maghnie M, Genovese E, Villa A, Spagnolo L, Campan R \& Severi F. Dynamic MRI in the congenital agenesis of the neural pituitary stalk syndrome: the role of the vascular pituitary stalk in predicting residual anterior pituitary function. Clinical Endocrinology 199645 281-290. (doi:10.1046/j.1365-2265. 1996.00789.x)

14 Maghnie M, Moretta A, Valtorta A, Larizza D, Sayegh M, Greco AM, Castoldi E \& Severi F. Growth hormone response to growth hormone-releasing hormone varies with the hypothalamic-pituitary abnormalities. European Journal of Endocrinology 1996135 198-204. (doi:10.1530/eje.0.1350198)

15 Maghnie M, Villa A, Arico M, Larizza D, Pezzotta S, Beluffi G, Genovese E \& Severi F. Correlation between magnetic resonance imaging of posterior pituitary and neurohypophyseal function in children with diabetes insipidus. Journal of Clinical Endocrinology and Metabolism $1992 \quad \mathbf{7 4}$ 795-800. (doi:10. 1210/jc.74.4.795)

16 Maghnie M, Cosi G, Genovese E, Manca-Bitti ML, Cohen A, Zecca S, Tinelli C, Gallucci M, Bernasconi S, Boscherini B, Severi F \& Arico M. Central diabetes insipidus in children and young adults. New England Journal of Medicine 2000343 998-1007. (doi:10.1056/NEJM200010053431403)

17 Ghirardello S, Garre ML, Rossi A \& Maghnie M. The diagnosis of children with central diabetes insipidus. Journal of Pediatric Endocrinology \& Metabolism 200720 359-375. (doi:10.1515/ JPEM.2007.20.3.359)

18 Traggiai C \& Stanhope R. Endocrinopathies associated with midline cerebral and cranial malformations. Journal of Pediatrics 2002140 252-255. (doi:10.1067/mpd.2002.121822)

19 Schaff-Blass E, Robertson GL \& Rosenfield RL. Chronic hypernatremia from a congenital defect in osmoregulation of thirst and vasopressin. Journal of Pediatrics 1983102 703-708. (doi:10. 1016/S0022-3476(83)80237-6)

20 Halter JB, Goldberg AP, Robertson GL \& Porte D Jr. Selective osmoreceptor dysfunction in the syndrome of chronic hypernatremia. Journal of Clinical Endocrinology and Metabolism $1977 \mathbf{4 4}$ 609-616. (doi:10.1210/jcem-44-4-609)

21 De Morsier G. Studies on malformation of cranio-encephalic sutures. III. Agenesis of the septum lucidum with malformation of the optic tract. Schweizer Archiv für Neurologie und Psychiatrie 1956 77 267-292.

22 Hoyt WF, Kaplan SL, Grumbach MM \& Glaser JS. Septo-optic dysplasia and pituitary dwarfism. Lancet 1970 1 893-894. (doi:10.1016/S0140-6736(70)91717-4)

23 Masera N, Grant DB, Stanhope R \& Preece MA. Diabetes insipidus with impaired osmotic regulation in septo-optic dysplasia and agenesis of the corpus callosum. Archives of Disease in Childhood 199470 51-53. (doi:10.1136/adc.70.1.51)

24 Dattani MT, Martinez-Barbera JP, Thomas PQ, Brickman JM, Gupta R, Martensson IL, Toresson H, Fox M, Wales JK, Hindmarsh PC, Krauss S, Beddington RS \& Robinson IC. Mutations in the homeobox gene HESX1/Hesx1 associated with septo-optic dysplasia in human and mouse. Nature Genetics 1998 19 125-133. (doi:10.1038/477)

25 Arslanian SA, Rothfus WE, Foley TP Jr \& Becker DJ. Hormonal, metabolic, and neuroradiologic abnormalities associated with septo-optic dysplasia. Acta Endocrinologica 1984107 282-288. (doi:10.1530/acta.0.1070282)

26 Stanhope R, Preece MA \& Brook CG. Hypoplastic optic nerves and pituitary dysfunction. A spectrum of anatomical and endocrine abnormalities. Archives of Disease in Childhood 198459 111-114. (doi:10.1136/adc.59.2.111) 
27 Kelberman D \& Dattani MT. Hypothalamic and pituitary development: novel insights into the aetiology. European Journal of Endocrinology 2007157 (Suppl 1) S3-S14. (doi:10. 1530/EJE-07-0156)

28 Baylis $\mathrm{PH} \&$ Robertson GL. Plasma vasopressin response to hypertonic saline infusion to assess posterior pituitary function. Journal of the Royal Society of Medicine 198073 255-260.

29 Thompson CJ, Bland J, Burd J \& Baylis PH. The osmotic thresholds for thirst and vasopressin release are similar in healthy man. Clinical Science 198671 651-656.

30 Thompson CJ, Selby P \& Baylis PH. Reproducibility of osmotic and nonosmotic tests of vasopressin secretion in men. American Journal of Physiology 1991260 R533-R539.

31 Rooke P \& Baylis PH. A new sensitive radioimmunoassay for plasma arginine vasopressin. Journal of Immunoassay 19823 115-131. (doi:10.1080/15321818208056990)

32 Robertson G. Posterior pituitary. In Enocrinology and Metabolism, edn 4th, pp 217-257. Eds P Felig \& L Frohman. New York: The McGraw Hill, 2001.

33 Ball SG, Vaidja B \& Baylis PH. Hypothalamic adipsic syndrome: diagnosis and management. Clinical Endocrinology $1997 \mathbf{4 7}$ 405-409. (doi:10.1046/j.1365-2265.1997.2591079.x)
34 Bourque CW. Central mechanisms of osmosensation and systemic osmoregulation. Nature Reviews. Neuroscience 20089 519-531. (doi:10.1038/nrn2400)

35 Cameron FJ, Khadilkar VV \& Stanhope R. Pituitary dysfunction, morbidity and mortality with congenital midline malformation of the cerebrum. European Journal of Pediatrics 1999158 97-102. (doi:10.1007/s004310051026)

36 Antonini SR, Grecco Filho A, Elias LL, Moreira AC \& Castro M. Cerebral midline developmental anomalies: endocrine, neuroradiographic and ophthalmological features. Journal of Pediatric Endocrinology \& Metabolism 200215 1525-1530. (doi:10.1515/ JPEM.2002.15.9.1525)

37 Smith D, McKenna K, Moore K, Tormey W, Finucane J, Phillips J, Baylis P \& Thompson CJ. Baroregulation of vasopressin release in adipsic diabetes insipidus. Journal of Clinical Endocrinology and Metabolism 200287 4564-4568. (doi:10.1210/jc.2002-020090)

Received 13 May 2011

Revised version received 10 July 2011

Accepted 12 July 2011 